Third International Engineering Systems Symposium

CESUN 2012, Delft University of Technology, 18-20 June 2012

\title{
Role of Flexibility in Sustainable Port Development
}

P. Taneja ${ }^{1}$, T. Vellinga ${ }^{2}$, R. Ros $^{3}$

${ }^{123}$ Delft University of Technology

Faculty of Civil Engineering

PO Box 5048, 2600 GA Delft, The Netherlands

p.taneja@tudelft.nl, t.vellinga@tudelft.nl, robin.ros@mail.com

\begin{abstract}
Sustainability has become a high profile objective in all aspects of our lives, including the development of our infrastructures. Flexibility can enhance sustainability endeavors, yet its contribution is not clear to most. In this paper we investigate the role of flexibility in sustainable port development in order to promote its incorporation in port projects. We establish that the greatest payoffs from flexibility are achieved through initiating new life cycle for a capital intensive port infrastructure, though reuse of the elements and materials also contributes to flexibility. Reuse concurrently optimizes use of natural resources, limits waste and pollution in the environment, conserves energy, and thus limits the overall negative ecological impact. It also results in significantly lowers lifecycle costs. Thus flexibility helps achieve (long-term) financial viability in face of economic uncertainty, while reducing environmental and social impacts. Therefore, flexibility considerations are important during design, procurement, and contracting of engineering projects. The best way to redirect the choice of decision-makers towards flexibility is to make visible its long-term benefits, and its contribution to sustainability. We discuss some evaluation methods and propose that the quantitative methods are more likely make a case for flexibility.
\end{abstract}

Keywords. Flexibility; Sustainability; Sustainable port development; Reusability; long-term planning

\section{Introduction}

The global concerns over availability of natural resources, the growing pollution, global warming, climate change, and an increasing awareness are the major drivers for sustainability in the modern world today. It is believed that sustainability represents a multi-dimensional way to improve the quality of life for everyone. Sustainable development touches all aspects of our lives including the places we work and live, the natural recreational pleasures we enjoy and the natural resources that 
support all life. Much attention is being devoted to how the practice of sustainable development, in contrast to the traditional linear approaches to decision-making, could be helpful in evaluating policy choices or business decisions (Flint, 2010; Willard, 2002).

Sustainable development of infrastructures, which are the skeleton of our economy, is also a focus of considerable attention. The decision-makers involved in infrastructure projects must select among different project and project alternatives, which, in varying degrees, contribute to sustainability. Till recently, the evaluation has mostly been based on an economic criteria but nowadays various sustainability criteria are being included in the process. Many claim that flexibility in infrastructures enhances sustainability attributes through addressing uncertainty (Neufville (2006), Greden (2005)). Though flexibility is often among the selection criteria during project evaluation, it is not assigned a significant weight, mainly because its contribution to sustainability is not clear to most.

In this paper we investigate the role of flexibility in sustainable port development. Our objective is to promote its incorporation during design and planning of port infrastructures. We think that by making clear its contribution in enhancing sustainability endeavors, we can redirect the choice of planners and decision-makers towards flexibility.

Our research approach is to first investigate what sustainability and flexibility represent in the context of ports. Next, we seek a link to flexibility - what dimensions of sustainability does it influence and in what manner? Finally we ask ourselves how we can direct the focus towards flexibility in practice, i.e., during design, procurement, and contracting of civil engineering projects.

\section{Sustainable Port development}

\subsection{Port development project}

Infrastructures represent the basic services and facilities necessary for an economy to function (Sullivan and Sheffrin, 2003). Port infrastructures are an essential component of the international trade and goods movement. Currently, a global increase in trade and cargo throughput, overlapping port hinterlands and increasing competition, combined with the ageing and inadequate infrastructure in most ports worldwide, are driving forces for new port investments.

A port development project can mean an entirely new port, or an expansion and upgrading of the existing facilities. The Chairman of American Association of Port Authorities notes (Hinds, 2008): "Ports hold a unique role in transportation, logistics and infrastructure development. Sustainability involves the simultaneous pursuit of economic prosperity, environmental quality of social responsibility. Ports recognize that their activities may impact environment and natural resources and that they have responsibilities as members of communities in which they operate."' 
Any development project has economic, environmental, and social impacts. A port development project can involve reclaiming land (thereby disturbing the eco-system) or sometime even causing displacement of the urban population. The vessel traffic and development activities translate into air quality, water quality, and noise issues; environmental management issues; and often accessibility issues for the adjacent areas. One can see why 'sustainable' and 'development' are seen to be oxymorons. Another contradiction is that while principles of sustainability advocate production close to centers of consumption this results in reduced transport and international trade on which ports (and related economies) are dependent. Having said this, we will attempt to operationalize the concept of sustainability and the idea it promotes in the next section.

\subsection{Sustainable development}

Sustainable development of infrastructures requires that carrying out activities that offer economic benefits in the present, may not negatively affecting social and environmental choices that are available to people in the future. Ports contribute to economic benefits through cargo handling, and produce additional indirect benefits in the form of trade enhancement, second order increases in production volumes, and collateral increases in trade-related services, and to the social dimension of sustainability through lowered transportation costs and job creation (World Bank and IBRD, 2007). Sustainable development of port includes designing, building, and operating port infrastructures in ways that does not diminish the social, economic, and ecological processes required to maintain human equity, diversity, and the functionality of natural systems ${ }^{1}$. The three aspects are discussed here.

The planning and design of new port infrastructures, or the adaptation and reuse of existing infrastructure, should be consistent with the principles of urban sustainability and global sustainable development. This encompasses the following considerations (as we will see in the next section, flexibility contributes directly to most of these):

- $\quad$ an efficient (intensive) use of space

- $\quad$ efficient use of resources and increased productivity of assets

- $\quad$ attention for accessibility of the port

- minimizing energy consumption

- greater consideration of cost recovery of port infrastructure investments

- reducing lifecycle costs (the taxpayers money can be put to alternative uses)

- designing infrastructure and its elements for reuse, e.g., recyclable, maintainable

- material selection for sustainability e.g., quality, durability and energy conservation

- as far as possible future-proof (with regard to technological developments, global climate change, sea level rise etc.)

Sustainability during construction and operations generally means measures related to resource and energy efficiency during material selection and construction as well as selection of equipment, logistic concepts, and operations. It involves monitoring air and water quality, implementing mitigating actions, ensuring health, safety and

\footnotetext{
${ }^{1}$ http://www.civ.utoronto.ca/sir/default.htm
} 
security, efficient use of resources (water, space etc). In the long run, the ultimate desire is to achieve a situation whereby the ports operations become environmentally self servicing and responsible (Transnet, 2010).

\section{Flexibility in port development}

\subsection{Defining flexibility}

Sustainability and flexibility are multi-dimensional concepts and various definitions exist in literature. They have an inherent relationship to each other as well as with the concepts of risk and uncertainty. Moses (2004) in his framing paper over 'Foundational issues in Engineering systems' explores the relationship between robustness, uncertainty, flexibility, safety, and sustainability. Dovers and Handmer (1992) study the relationship between sustainability, risk, and uncertainty. In order to investigate the relationship between sustainability and flexibility, we first examine some definitions.

Sanchez and Wilmsmeijer (2005) define flexibility, in generic terms, as the ability of a system or organization to change or react with little penalty in time, effort, cost, or performance. Bettis (1995) define flexibility as the ability to rapidly sense the change in the environment, conceptualize a response to that change, and reconfigure resources to execute that change. According to Dovers (1991), sustainability is the ability of a human, natural or mixed system to withstand or adapt to endogenous or exogenous change indefinitely. Sustainable development is therefore a pathway of deliberate change and improvement which maintains or enhances this attribute of the system, while answering the needs of the present population.

Thus while both definitions refer to system change in response to external forces, sustainability adds new dimensions by mentioning 'future' and 'long-term'. Flexibility implies 'long term' through its reference to uncertainty. Both refer to resource utilization. Flexibility enables functionality under uncertain conditions and emerging requirements while sustainability adds economic, social and environmental dimensions to the system.

\subsection{Flexibility attributes and sustainability}

Scholtes (2007): The most important uncertainty management concept for large projects is that of flexibility. Managers should integrate flexible reaction capacity in the project, so that new schemes can be developed during the course of the project if a wholly unforeseeable event occurs. Predicting the uncertain future is difficult, but to the extent one can use past events as a guide to designing flexible alternatives or options into a system, the cost of adapting to similar events in the future will be greatly reduced (Moses, 2004).

The word flexibility in the context of ports can have many associations, e.g., flexible port layout, flexible infrastructures, flexible operations, flexible management, etc. We 
discuss here, how each of these aspects contributes to sustainability. In each case, the goal of flexibility is the same - to reduce vulnerability and cope with uncertainty.

- Flexible infrastructures conjure up the images of mobile, upgradable, downgradable, modular, multi-functional, multi-user structures. What is common to all of these is the ability to adapt, i.e. be remodelled to meet changing demands.

- A flexible Master Plan layout permits reconfiguration of a space for a new or changed use.

- Flexible operations can refer to flexible use of resources (labour, equipment, etc.) and flexible operating procedures, in response to changing scale or type of operations.

- A flexible management is willing to alter its approach in response to unanticipated change with regards to planning, decision-making, policies, and actions.

A flexible layout allows future expansion, and permits re-configuration without expensive modifications. Flexibility in infrastructure helps to prolong the useful lifetime of an infrastructure through allowing adaptation and thus promoting reusability. Reuse concurrently optimizes use of natural resources, limits waste and pollution in the environment, thereby reducing the overall ecological impact. It also results in significantly lowers lifecycle costs (despite the costs associated with incorporation of flexibility and subsequent adaptations) and conserves energy resources. The savings can be invested in improving social equity or the environment. In this manner flexibility helps achieve (long-term) financial viability in face of economic uncertainty, while reducing environmental and social impacts. A sustainable product is often referred to as a product whose economic benefits that outweigh its tangible and intangible costs so as to provide financial capital for continued development (Greden, 2005) - as we have seen, flexibility makes this possible.

The greatest payoffs are achieved through the reuse of the capital intensive infrastructure whereby a new life cycle is initiated. This type of reuse is the highest form of waste reduction. However, reuse as components or raw materials integrates the structure into a life cycle of another structure and also contributes to sustainability. Recovery from products to obtain raw materials or reusable components is an important means of reducing disposal volume and cost while contributing to environmental sustainability.

It is useful to note here that attributes such as interoperability, interchangeability, compatibility, scalability, evolvability, and mobility facilitate adaptation and reuse. In addition, maintainability and durability promote reuse of an infrastructure. A structure that is easy to dismantle or assemble facilitates reuse of its elements. Recyclability promotes reuse of material. Flexibility is often aimed at improving efficiency, productivity, and reducing engineering effort and costs. These contribute to sustainability endeavours as well. Even though adaptation incurs costs, a payoff occurs in the form of lowered ecological impact. De Neufville et al. (2005): A flexible design will have a different risk-reward profile than an inflexible system, and thus may be more attractive to investors. Flexible designs will help to advance sustainability goals by specifically addressing future uncertainty at the design stage. 
While flexible designs create many benefits in the system, flexible (uncertainty absorbing contracts) with the terminal operators and contractors, reduce the future risk for a Port Authority. Flexible utilization of resources during operation, sometimes geared to changing scales (in response to change in demand) and at other times to changing cargo, serves to intensify use of resources, thereby contributing to sustainability. An adaptive management willing to periodically re-examine its assumptions, and adopt new strategies and procedures in the face of new developments, can steer a firm to cope with change. Flexibility during decisionmaking allows time for uncertainty to clear up.

To sum up in words of Greden (2005): Flexibility's contribution to sustainability goals lies in reducing waste and/or positioning a product/design/or system with sustainability benefits to hedge financial risk and, on the upside, to take advantage of evolving opportunities.

\subsection{Flexibility and sustainability as a design approach}

The traditional approaches and frameworks tend to emphasize near term solutions to infrastructure planning, which means that there is inadequate attention for sustainability (Cutcher-Gershenfield, 2004). Flexibility, on the other hand requires a holistic, long-term systems approach. Through aspiring for flexibility, we include a long-term perspective, which automatically encompasses uncertainty considerations and embraces issues that might be important in the future. Designing for flexibility fundamentally embodies a life-cycle approach to design, whereby lifecycle costs and long-term performance have to be considered. This also applies to sustainability which needs a systems approach: accepting and designing approaches which suit the axiomatic proposition that the sustainability problem is a whole-system problem (Dovers, 1992).

Designing for flexibility and sustainability requires that projects and decisions be made with the long term benefits in mind. It requires that environmental and social impacts of the proposed outcome or result be a part of the decision-making process. Flexibility and sustainability considerations are required at the beginning of a project. For instance, the cost of recycling and disposability can be significantly affected by decisions related to materials and designs. They require a systematic approach to the integrated design which considers from the very outset all elements of the product life cycle, from conception to disposal, including cost, schedule, quality and user requirements.

According to Greden (2005), flexibility, as a design goal and operational mandate, can make a major impact on the sustainable attributes of an infrastructure. Applying her definition of a sustainable product, a sustainable port exhibits a positive economic, environmental, health, and safety performance record, thereby providing people and the earth, including all of its ecosystems and life forms, with the capacity to thrive in future generations. 


\section{Opting for flexibility and sustainability}

\subsection{Standard practices}

A port project goes through various stages: preliminary design, feasibility study, detailed design, tendering and construction, exploitation, and adaptation or decay. Evaluation and selection takes place at the feasibility stage and the tender stage.

Feasibility stage: Engineers from various disciplines carry out the technical design, and a business case is set up to examine the financial viability of a project. The Net Present Value and the Internal Rate of Return are the most commonly used financial criteria. Uncertainty is only reflected in a higher discount factor or a shorter payback time. It seems self evident, in present times, to take uncertainty, flexibility and sustainability aspects related to a port into account during the evaluation. This is however not standard practice, and can lead to misguided decisions. Worthwhile projects may not pass the (financial) feasibility criteria for screening projects and result in missed opportunities for the port, along with lost benefits for the society (Taneja, 2010).

In the present practice, the indirect and societal impacts of a port development project are stated separately in the business case, while remaining outside the profitability calculations. This involves a risk that societal impacts are represented less prominently than financial items so that the business case is not balanced. In marginal cases, an attempt is made to include the societal costs and benefits in a port development business case. But it is difficult to justify this to the port management, as it does not form a part of the standard procedure of project evaluation. As a result, the commercial criterion mostly governs.

Tender stage: Next, the selected alternative is put on the market in a tender in order to select a contractor to carry out the construction. The selection is based on the EMVI criteria $^{2}$ (or the lowest bid). But an evaluation based purely on costs, and the constraint on the tenderer not to offer alternative designs but base his bid on a reference design, does not propagate innovation. In an alternative method, the landlord port authority sets out a design and construct contract, where the total bid including the design and the construction has to be evaluated. The decision is based on the cost of the project, and not on its value. The added value of an innovative flexible concept is to increase utilization, productivity and consequently increase income and minimize risks. This cannot be revealed through cost estimation.

People, Planet and Profit are used to succinctly describe the triple bottom lines and the goal of sustainability. How to include the people, profit and planet criteria in such an evaluation procedures, is a challenge for all.

\footnotetext{
${ }^{2}$ Economisch meest voordelige inschrijving
} 


\subsection{Incorporating flexibility criteria in evaluation}

In this section, we discuss how sustainability is implemented in the tendering procedure for infrastructural projects, and examine how we can best implement flexibility.

Sustainability has become a high profile objective. Decision-makers in governments and businesses must choose among different project alternatives which, in varying degrees, contribute to sustainability. They also have to account for their choices to a large audience or a broad range of stakeholders (Sijtsma, 2006). The organisation for economic cooperation and development (OECD) has drawn up recommendations for corporate social responsibility, which includes principles and standards of good practice consistent with applicable laws for multinational enterprises ${ }^{3}$.

Sustainability criteria being considered during evaluation are: the extent of occupied space, reduced land value due to division of land, additional traffic generated due to the construction, deterioration of existing nature, emissions in air and in surface and ground water, nature compensation measures, creation of nature-friendly banks and slopes, implementation of an environmental management system, attention for energy demand, measures concerning disposal of waste materials, measures against noise during demolition, construction and operations, reuse of material, attention for ecological constraints, e.g. amount of earth filling, soil quality etc. In the Netherlands, the $5 \%$ rule (or social return agreement) is applicable whereby $5 \%$ of the building sum is set towards employing long time unemployed or trainees.

Flexibility in decision-making, design and operations, enhances the value of a project, but cannot be included in the project evaluation with standard methods. Though efficient use of space and reuse of material are among the many evaluation criteria, flexibility in its highest form (reuse of infrastructure) is not included. Its contribution to sustainability is not clear to most, i.e., what does flexibility cost and what value will it create for the system?

Not only are the (positive) economic impacts of reusability difficult to estimate, the benefits of reduced environmental impacts are also difficult to quantify. The multidimensional nature of flexibility, and the likelihood that the flexibility may not be utilized and therefore result in a waste of resources, adds to the problem. Flexible innovative concepts carry with them considerable risks which are difficult to foresee. So how we can redirect the decision-makers to opt for innovative flexible solutions over the numerous alternatives?

The lack of suitable analytical and evaluation techniques has been a barrier against investments in flexibility in the past. New techniques have evolved, but their use is not widespread due to their black-box approach. We need to find ways to make visible and transparent the long-term benefits of flexibility such as optimum use of resources, lower lifecycle costs, better long-term performance, and minimization of negative environmental impacts. In case of a traditional tendering procedure this needs to be done at the feasibility stage, while in case of a design and construct contract, this is possible during the tender evaluation.

\footnotetext{
${ }^{3}$ http://www.oecdguidelines.nl/guidelines/general-humanrights/
} 
In this paper we limit ourselves to investigating how we can include reuse or an extended economic lifetime in our evaluation.

\subsection{Some plausible methods}

\section{Method 1: A variation on the traditional approach}

This is a variation on the traditional method which combines a qualitative and quantitative approach. The NPV is evaluated based on the tangible costs and benefits for each alternative. The intangible costs and benefits for each alternative are also listed. Flexibility criteria related to reuse can be added to this, and a qualitative evaluation carried out for each alternative. The criteria follow from the Delftse Ladder, (Dobbelsteen and Alberts, 2001). These can be assigned weights based on expert opinion and included in the evaluation. It can be applied at the feasibility stage, or at the tender stage, using costs instead of revenues.

- Is the infrastructure reusable for another use without adaptation (is it robust against increased loads, bigger ships, another function)?

- If yes, how long (5-10 years, 10-15 years, 15-20 years)?

- Is the infrastructure reusable for another function with adaptation?

- If yes, how long (5-10 years, 10-15 years, 15-20 years)?

- What will the adaptation cost (as a percentage of capital costs: $0-10 \%, 10-20 \%$, 20-30\%)?

- Are there reusable elements/components?

- Is the structure modular?

- Are the elements easy to dismantle, transport, and assemble?

- Are there reusable/ recyclable materials?

The last two are the most commonly applied sustainability criteria.

The many uncertain parameters and the qualitative nature of the method means that the evaluation is subjective. Therefore a fair comparison of alternatives may be specially difficult if the alternatives are similar. Willcocks (1994) suggests that managers should enter alternative estimates of intangible benefits (e.g. minimum and maximum values) into the NPV model to explore the project's sensitivity to the delivery of these intangibles. Another shortcoming is that it is impossible to link the synthesized rating to business plans or to cash flow projections (Milis, 2009).

\section{Method 2: Use of scenarios}

In this method, the port owner or Authority defines the technical lifetime of the infrastructure (say 50 or 100 years) and sketches a discrete number of alternative scenarios. Each scenario encompasses functional requirements for the infrastructure, a period of use, and the expected throughput. A design is made corresponding to each scenario and its NPV calculated. In this way, a range of NPV's is obtained which provides more information for decision support. These scenarios are merely plausible descriptions of the future, and the results are indicative, but adequate for the purpose of comparing alternatives. A range of NPV's also provides an indication of the risk and the selection will depend on the risk attitude of the manager. If most of the design parameters are a given, the flexibility in design (robust, upgradable, multifunctional, 
multi-user) will be reflected in the NPV values. Many oppose the use of scenarios as being guess work.

\section{Method 3: Expected value method}

This is a variation of Method 2. A stochastic business case is set up at the feasibility stage. It can vary all uncertain inputs (future costs, revenues, and timing of investments) simultaneously, and is of great value in infrastructure planning and appraisal. It also captures the complicated nature of contractual arrangements and payment mechanisms, incorporates the probability of an increase in throughput and can include available flexible options in a project. It results in a range and distribution of the possible NPV outcomes and the likelihood of their occurrence. A probabilistic estimation of risks for all the projects in the portfolio provides an organization with a more realistic risk map that can influence their risk attitude, and allow them to timely steer their policies.

Discussion: Methods 2 and 3 can both be applied to take into account the flexibility attributes of an infrastructure (see Ros (2011) and Taneja (2011)). None of the above methods include indirect, i.e. social and environmental benefits of reuse. More research is required in order to monetize these in order to come up with a comprehensive evaluation model.

\section{Conclusions}

A global increase in trade, increasing competition, and inadequate infrastructure are driving forces for new port investments worldwide. Ports recognize that their activities impact environment and natural resources, and seek a balanced approach for sustainable development. Sustainability has become a high profile objective. Flexibility can play a role in enhancing sustainability, yet its contribution is not clear to most. In this paper we investigate the role of flexibility in sustainable port development in order to promote its incorporation in port infrastructures.

The greatest payoffs from flexibility are achieved through initiating new life cycle for a capital intensive port infrastructure, and to a lesser extent through reuse of elements and materials. Reuse concurrently optimizes use of natural resources, limits waste and pollution in the environment, conserves energy, and reduces limits overall ecological impact. It also results in significantly lowers lifecycle costs (despite the costs associated with incorporation of flexibility and subsequent adaptations). Thus flexibility helps achieve long-term financial viability in face of economic uncertainty, while helping environmental and social problems. We need to focus on flexibility in practice, i.e., during design, procurement, and contracting of civil engineering projects.

That flexibility may or may not be utilized in the future, acts as a big deterrent while making the decision to incorporate it. In order redirect the choice of decision-makers towards flexibility, the best way is to make visible the long-term benefits and thus its contribution to sustainability. We discuss three plausible methods which can include the costs and benefits of reuse during evaluation. (Reuse is facilitated by the 
flexibility attributes in a system, such as multi-functionality, scalability, modularity, and mobility, etc. which means added costs). We think that the quantitative methods are more likely make a case for flexibility. More research is required in order to monetize the other indirect and direct impacts of flexibility, to come up with a comprehensive evaluation model.

Acknowledgments This research is carried out within the framework of Port Research Centre Rotterdam-Delft and Next Generation Infrastructures.

\section{References}

Bettis, R. and Hitt, M. (1995), The new competitive landscape. Strategic Management Journal, 16(7).

Cutcher-Gershenfield, J. F. and Field, F. and Hall, R. and Kirchain and Marks, R. D. and Oye, K. and Sussman, J. (2004), 'Sustainability as an organizing design principle for largescale engineering systems', Paper presented at the MIT Engineering Systems Symposium, 29-31 March, at MIT, Cambridge, Mass. Available http://esd.mit.edu/symposium/monograph, sccessed 1, April, 2008.

Dobbelsteen, van den A. and Alberts, K. (2001), Milieueffecten van bouwmaterialen: duurzaam omgaan met grondstoffen. Available http://www.wegwijzerduurzaambouwen.be/pdf/174.pdf, accessed 1 April 2009.

Dovers, S. (1991), 'Diverse and resilient approaches to sustainable development', in R. Harding, ed., Proceedings. Ecopolitics V Conference, Sydney, 4-7 April 1991, University of New South Wales, Sydney, pp 225-232.

Dovers, S. R. and Handmer, J. W. (1992), Uncertainty, sustainability and change, Global Environmental Change, December 1992, Available http://www.sciencedirect.com/science/article/pii/0959378092900448, accessed 1 April 2012.

Greden, L.V. (2005), Flexibility in building design: A real options approach and methodology to address risk. Phd Thesis, Massachusetts institute of Technology (MIT).

Hinds, A.A, (2008), Sustainability - An imperative for the port and maritime industries, AAPA Port Sustainability Task Force. Doing Well by Doing Good: Ports and the Sustainability Challenge, AAPA Port Finance Seminar, June 10-12, 2008.

Flint, R. W. (2010), Symbolism of Sustainability: Means of Operationalizing the Concept, Synesis: A Journal of Science, Technology, Ethics, and Policy 2010, 1(1):T25-37.

Milis, K. and Snoeck, M. and Haesen, R. (2009), Evaluation of the applicability of investment appraisal techniques for assessing the business value of IS services, Available https://lirias.kuleuven.be/handle/123456789/247210, accessed 1 April 2009.

Moses, J. (2004), Foundational issues in engineering systems: A framing paper. Available http://esd.mit.edu/symposium/pdfs/monograph/framing.pdf, accessed on 1 April 2008.

Neufville, de (2006), Valuing Options by Spreadsheet: Parking Garage Case Example, ASCE Journal of Infrastructure Systems, Vol. 12(2), pp.107-111. 
Ros (2011), Flexible Infrastructures for Maasvlakte 2, MSc thesis, Delft University of Technology.

Sanchez, R. and Wilmsmeier, G. (2005), Short sea shipping in central America to bridge infrastructural gaps. Maritime Policy and Management, 32(3):227.

Scholtes, S. (2007), Flexibility: The secret to transforming risk into opportunities. Business Digest, May 2007, No. 174:6.

Sullivan, A. and Sheffrin, S.M. (2003), Economics: Principles in action. Upper Saddle River, New Jersey 07458: Pearson Prentice Hall. pp. 474.

Taneja, P., Aartsen, M.E., Annema, J.A. and Ligteringen, H. (2010), 'Investment Appraisal for Sustainable Ports', Proceedings of 3e international conference on Next Generation Infrastructure Systems for Eco-cities, 11-13 November 2010.

Taneja, P., van Turnhout, B. and Aartsen, M.E. (2011), Infrastructure planning under uncertainty, Proceedings of the 4e international conference on Next Generation Infrastructure Systems for Eco-cities, 16-18 November 2011, Norfolk, USA.

Transnet (2010), Port sustainability and environmental challenge: A South African Perspective, The 1st eastern and southern ports environmental mangers working conference, 20-22 September 2010, Mombasa, Kenya.

Willard, B. (2002), The Sustainability Advantage: Seven Business Case Benefits of a Triple Bottom Line (Conscientious Commerce), New Society Publishers: British Columbia.

Willcocks L. (1994), Information management: the evaluation of information systems investments, Chapman \& Hall.

World Bank and IBRD (2007). Port Reform Toolkit: Effective Support for Policymakers and Practitioners (2nd edition), Available http://www.ppiaf.org/documents/toolkits/Portoolkit/, accessed 1 April 2008. 